\title{
An Empirical Research on the Factors Affecting Channel Collaboration in Multi-channel Supply Chain
}

\author{
From the Perspective of Manufacturers* \\ Min Wang \\ School of Economics \& Business Administration \\ Chongqing University \\ Chongqing, China 400044 \\ Chongqing Key Laboratory of Logistics \\ Chongqing University \\ Chongqing, China 400044
}

\author{
Xumei Zhang \\ School of Economics \& Business Administration \\ Chongqing University \\ Chongqing, China 400044 \\ Chongqing Key Laboratory of Logistics \\ Chongqing University \\ Chongqing, China 400044
}

\author{
Zijian Ding \\ School of Economics \& Business Administration \\ Chongqing University \\ Chongqing, China 400044 \\ Chongqing Key Laboratory of Logistics \\ Chongqing University \\ Chongqing, China 400044
}

\begin{abstract}
This paper analyzes the factors affecting multichannel collaboration from the perspective of manufacturers in the multi-channel supply chain in the aspects of manufactures themselves and their relationship. Five influencing factors were derived: channel tracing capability, reward coordination capability, manufacture's dependence, multi-channel conflicts and trust. On this basis, this paper establishes a conceptual model of the factors affecting channel collaboration in multi-channel supply chain by taking the collaborative performance of manufacturers as the outcome variable. Combined with the questionnaire data collected from 217 manufacturers, the conceptual model above was empirically tested by structural equation model. Results indicate that channel tracing capability, multi-channel conflicts and trust have a significant positive impact on the collaboration performance of manufacturers. However, manufacture's dependence has a significant negative impact, while the impact of reward coordination is not significant.
\end{abstract}

Keywords-multi-channel supply chain; channel collaboration; influencing factors; empirical research

\section{INTRODUCTION}

In recent years, more and more product manufacturers have actively added Online e-direct channel to the original traditional retail channel, forming multi-channel supply

*Project: The National Natural Science Foundation of China; Project No.: 71572020

The Basic Research Operating expenses Program of Central College, Project No.: 2017CDJSK02PT08.

Chinese Library Classification (CLC) number: F270.7.

Document code: A chain; and conducted cooperation between emerging electronic channels and traditional retail channels to meet the diversified demands of consumers. For example, Haier Group promotes the cooperation strategy that integrates the electronic channel, "Haier Shunguang Mall", and traditional channel, sales service center. The former is responsible for attracting orders online and alloting the orders to thousands of sales centers in different region while the latter for delivery and service, thus putting Haier in a ready position for providing national electricity consumption service. Although the multi-channel model can bring potential advantages such as competitive advantage and more market coverage to enterprises [1], there are also cooperation problems such as service overlapping and difficulties in distributing interests [2]. For example, Manufacturers like Levis, Apple, Yishion, and Daphne have faced competition and conflicts for channels, which affect the sales of channel members and lead to cooperation dilemma. [3] To successfully implement a multi-channel strategy, enterprises must first solve the issue of channel cooperation. Therefore, it is very important to analyze the factors affecting multichannel cooperation and to clearly define the mechanism for better cooperation performance [4]

In terms of existing research on multi-channel cooperation, there are qualitative research, mathematical model research and empirical research. Qualitative research mainly proposes corresponding management strategies from the perspective of multi-channel integration. For example, Zhang et al. [5] analyzed the motivations and limitations of multi-channel model adopted by retailers and the opportunities and challenges of channel synergy; Wang 
Guocai et al. [6] proposed the strategy that enterprises should put high goals, coordinate behaviors and strengthen communication in the whole channel, so as to realize multichannel integration through classified strategies in brand, price, product and so on. Other literatures have studied the issues of multi-channel business cooperation and benefit distribution through mathematical model method. The research on business cooperation mainly focuses on the areas of inventory coordination, information sharing, cooperative advertising, joint promotion, etc. For example, Chiang [7] analyzes the influence of the change in customer's demand on the performance of electronic direct sales channel and traditional retail channel when the channel is out of stock. The results show that manufacturers and traditional retailers can improve their channel performance through integrated inventory. Ai Xing Zheng et al [8] use the parametric variables in electronic direct sales channels and traditional retail channels - potential market share, competition intensity between channels, market risk, information prediction accuracy — to establish model analyzing the influence of information sharing on the performance of channel members. Yu Aimin et al [9] studied that with the joint promotion of manufacturers' electronic channel and traditional retail channel, the optimal price of electronic direct selling channel reduces as the increase in promotional efforts of retailers, as well as the benefits of both parties. The research on multi-channel member performance and cooperative income distribution mainly uses the contract mechanism such as channel price contract and revenue sharing to coordinate. For example, $\mathrm{Xu}$ et al. [10] investigated that when the retailers are risk-averse, the manufacturers promoted their cooperation with retailers through two-way revenue sharing contract to coordinate the dual-channel supply chain and ensure a win-win situation. There are few empirical studies on multi-channel collaboration. For example, Steinfield [11] investigated the degree of collaboration between retailers' websites and physical stores, analyzed the collaborative resources needed for channel integration, and verified the conclusion that enterprises with high integration and active coordination management will get higher returns. Gallino et al. [12] conducted empirical research on channel integration strategies in which multi-channel retailers use electronic channels to provide inventory inquiries to customers and pick commodities in physical stores. The above mathematical model research pays more attention to the single decision variables appearing in the channel cooperation, and fails to comprehensively consider the factors affecting channel cooperation. However, the existing empirical research mostly takes large foreign retail enterprises as the research object, and there are few empirical researches involving channel cooperation between merchants and traditional retailers in the multi-channel supply chain, and exploring the factors affecting multi-channel cooperation. However, the identification and analysis of the influencing factors of multi-channel cooperation is of great significance for manufacturers to improve the channel cooperation with traditional retailers.

Given this, this paper intends to use structural equation modeling to test the influencing factors and mechanism of multi-channel supply chain channel cooperation based on literature research and empirical data analysis from the perspective of manufactures, and provides useful ideas for reference and theoretical guidance for channel cooperation among multi-channel supply chain.

\section{ANALYSIS OF FACTORS AFFECTING MULTI-CHANNEL COOPERATION}

This paper analyzes the factors affecting multi-channel collaboration in the aspects of manufactures themselves and their relationship from the perspective of manufacturers based on the literature research of channel behavior theory and supply chain coordination: channel tracing capability, reward coordination capability, manufacture's dependence, multi-channel conflicts and trust. Manufacturers' factors include channel tracing capability and channel coordination capability. Factors in their relationship include: manufacturer dependence, multi-channel conflicts and trust. The channel cooperation effect affected by the factors is reflected by the cooperation performance, so as to construct the influencing factor model of the manufacturers' channel cooperation of the multi-channel supply chain. (See "Fig. 1"). The analysis of each influencing factor and corresponding assumptions are as follows.

\section{A. Manufacturer's Own Factors}

1) Channel tracing capability: Channel tracing capability refers to the ability of manufacturers to trace the product delivery and service delivery of channel members, including process tracing and results tracing. Wallace et al. [1] believe that service delivery downstream of the supply chain needs to be effectively controlled. Channel tracing capabilities such as frequent site visits and telephone communication are more important when the complexity of multi-channel increases. Manufacturers will increase the investment of certain assets, equipment, professionals and knowledge when implement the cooperation between electronic channel and traditional channel, and ensure that marketing strategies such as products and services are realized through joint actions and information sharing. For manufacturers, channel tracing capabilities are needed to guide and control the cooperative behavior of traditional retailers to prevent their speculative behaviors; they also need to evaluate the service of traditional channels and provide corresponding feedbacks to help improve their service. For traditional retailers, the channel tracing by manufacturers will be seen as an active promotion of channel cooperation, which can stimulate the cooperation of traditional channels, thus helping the two parties to improve cooperation performance. The author makes the following assumptions based on analysis above.

H1: Manufacturer's channel tracing capability has a positive impact on improving the performance of channel cooperation.

2) Reward coordination capability: Reward coordination capability is the ability of manufacturers to use 
incentives to coordinate the effort, outputs, and benefits of channel members. The key to effective management of supply chain is to integrate the resources of the supply chain to coordinate the efforts and outputs of all members [13], and incentive design is an important part of the coordination capacity of the supply chain [14]. The market share and revenue of traditional retailers are diluted because of the addition of manufacturers' electronic channels in the downstream of supply chain. If the traditional channels thus reduce the services provided and even exit, this will be deviate from the multi-channel strategic objectives of the manufacturer to meet the customer's comprehensive consumer experience. Therefore, while operating electronic channels, manufacturers need to use appropriate coordination mechanisms to encourage traditional retailers [7] [8] [9] [10], so that traditional channels can play their own advantages and conduct multi-channel cooperation to improve cooperation performance and make up for the impact of channel competition. Manufacturers with reward coordination capability will better encourage traditional retailers to cooperate, establish long-term stable cooperative relationships, improve performance and rationally distribute revenue. The author makes the following assumptions based on analysis above.

H2: Manufacturer's reward coordination capability has a positive impact on improving the performance of channel cooperation.

\section{B. Relationship Factors}

1) Manufacturer dependence: The interdependence of channel members stems from the demand for each other's resources [15]. According to the Resource Dependence Perspective, enterprises often need to obtain such key resources from the external environment, which is also applicable to channel relationships. [16]. Dependency is the basis of marketing channel behavior, providing channel members with the necessity of cooperation. With clear market division of labor, traditional retail channels rely on manufacturers' products for sales and circulation to obtain revenue, while manufacturers rely on the on-site sales services provided by traditional retail channels and shape brand loyalty of customers. Although manufacturers' electronic direct sales channels respect no geographical boundaries and can increase market coverage, they cannot provide the live experience brought by traditional channels to customers. Manufacturers need traditional channels to cooperate in various aspects such as service provision, inventory logistics and advertising promotion to improve channel efficiency. Since the distribution ratio of performance is often proportional to the level of service contribution, the greater their dependence of manufacturers on traditional channel services and collaboration, the more benefits will be alloted to traditional channels. The author makes the following assumptions based on analysis above.
H3: Manufacturer dependence has a negative impact on improving the performance of channel cooperation.

2) Multi-channel conflict: The emergence of electronic direct sales channels has enabled manufacturers to directly participate in competition in horizontal channels with traditional channels, and such competition has imposed new pressure on traditional retailers. Zhang et al. [4] believe that the conflict between traditional retailers and electronic channels mainly comes from the fear that the electronic channels will obtain most market share. Balasubramanian et al. [17] pointed out that when new customers reach other channels and incurred indirect or direct competition with traditional channels, multi-channel conflicts will occur. Customers can turn to electronic channels to complete purchases after experiencing products and services in traditional channels. Such "free rider" behavior may lead to conflicts between traditional channels and electronic direct sales channels in product pricing, market segmentation, promotion and profit distribution, undermining the existing cooperation relationship. However, some studies have pointed out that although conflicts in partnerships are inevitable, the consequences are not necessarily bad [18], and measures can be taken to prevent harmful or high-level conflicts from arising. Webb et al. [2] believe that if there are no channels conflict, channel members will become less active and less creative. When a conflict arises, the manufacturer will actively coordinate and promote cooperation between the two parties to achieve a multichannel profit strategy. This paper tends to advocate the positive effects of multi-channel conflicts and makes assumptions based on the analysis above.

H4: Multi-channel conflicts have a positive impact on improving the performance of channel cooperation.

3) Trust: Trust is the positive confidence, attitude and expectation that the other party's actions and results will satisfy themselves. There are more uncertainties in the supply chain cooperation relationship, and trust plays an important role in the cooperation process [19]. When manufacturers implement multi-channel cooperation, if traditional retailers' business experience, resource advantages, and ability to perform cooperation are recognized and trusted, manufacturers will reduce forecasts and temptations for retailers and reduce interaction costs with retailers [20], to promote the true cooperative behavior of the manufacturer. In addition, after establishing trust with traditional retailers, manufacturers will release the signals of cooperation by transmitting sales strategies, sharing customers and market resources, so that traditional retailers can deepen their trust in manufacturers and believe that manufactures will not use the electronic channel to damage the interests of traditional channels, so as to fully participate in cooperation and share profit. The author makes the following assumptions based on analysis above.

H5: Trust has a positive impact on improving the performance of channel cooperation. 


\section{Cooperation Performance}

Cooperative performance is the ultimate manifestation of the results of cooperation between channel members. In terms of evaluation of channel performance, Geyskens et al. evaluate it with channel members' satisfaction level for financial performance and non-financial performance [21]. As regards to evaluation of inter-enterprise cooperation performance, Lyles et al. believe that subjective indicators such as the degree of achievement of cooperation goals can be used to evaluate cooperation performance [22]; Mohr et al. pointed out that the cooperative members' degree of satisfaction is also a key factor to measure the success of the partnership [23]. Therefore, this study has made applicability changes, established financial performance relative indicators and relationship performance indicators to measure channel cooperation performance. For specific metrics, please refer to the questionnaire item scale. (See "Table I")

This paper proposes corresponding conceptual model based on the above theoretical analysis and assumptions (See "Fig. 1")

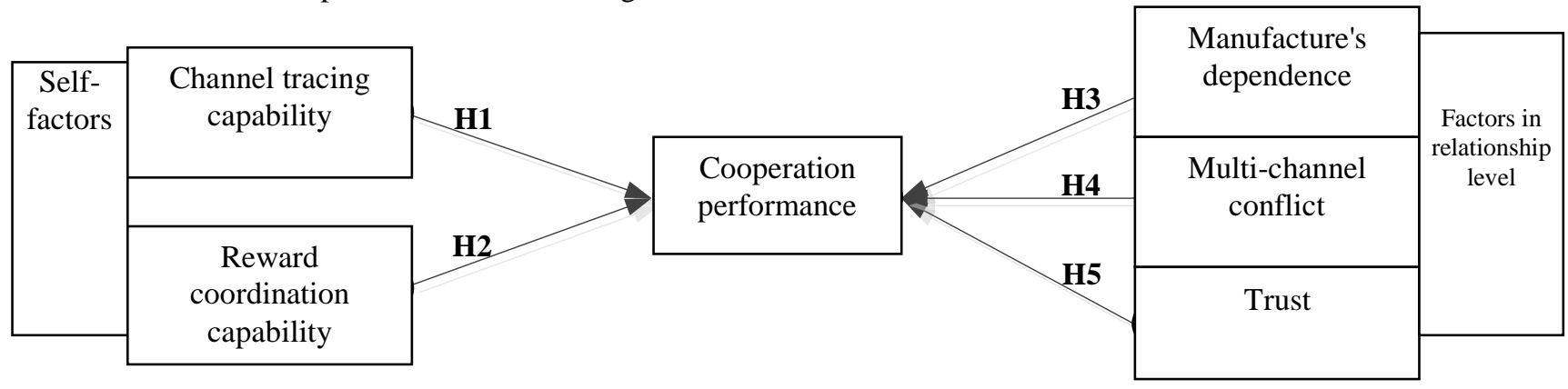

Fig. 1. Conceptual model and hypotheses.

\section{RESEARCH DESIGN AND DATA COLLECTION}

\section{A. Questionnaire Design}

The research object of this paper is the manufacturer who implements the cooperation between electronic direct selling channel and the traditional channel in the multi-channel supply chain. This paper carried out preliminary design of the questionnaire and conducted detailed investigations on the local multi-channel manufacturers based on the literature research, as well as understood the influencing factors variables proposed by the hypothesis through interviews and questionnaire. After the influencing factors were confirmed, the researchers asked for revision opinions from experts in enterprises and universities on the questionnaire test items, and finally completed the questionnaire design through a small sample of pre-tests. The items in the questionnaire were based on the Likert five-level scale method, with 1 to 5 indicating Strongly disagree, disagree, uncertainty, agree and totally agree. The final variables, measurement indicators and references are shown in "Table I":

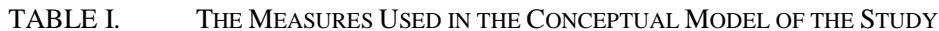

\begin{tabular}{|c|c|c|}
\hline Research variable & Measurement standard & Reference source \\
\hline $\begin{array}{l}\text { Channel tracing } \\
\text { capability }\end{array}$ & $\begin{array}{l}\text { CT1 frequent visit to retailers of traditional channels to ensure that the employees understand the products } \\
\text { offered. } \\
\text { CT2 tracing the time and effort spent by retailers to train employees to sell products in traditional channels . } \\
\text { CT3 a program for evaluating the long-term service effectiveness of retailers in traditional channels. } \\
\text { CT4 supervising the product knowledge level and training level of promoters in traditional channel. } \\
\text { CT5 a special program to find out if customers are satisfied with retailer in traditional channel. } \\
\text { CT6 obtaining information from end customers to evaluate whether retailers in traditional channels provide good } \\
\text { service to customers. } \\
\text { CT7 offering feedback information to retailers in traditional channels to improve service. } \\
\text { CT8 evaluating the service of retailers in traditional channel based on a specific set of performance criteria. }\end{array}$ & \multirow[b]{2}{*}{$\begin{array}{l}\text { Wallace et al } \\
(2009)\end{array}$} \\
\hline $\begin{array}{l}\text { Reward } \\
\text { coordination ability }\end{array}$ & $\begin{array}{l}\text { RA1 Despite competition from electronic channels, products offered are able to make profit for retailers in } \\
\text { traditional channels. } \\
\text { RA2 While employee training and inventory increase costs, retailers in traditional channels can still rely on the } \\
\text { products to earn profit. } \\
\text { RA3 Despite competition from other channels, retailers in traditional channel will give corresponding support as } \\
\text { they can ger profit from the products. } \\
\text { RA4 Despite the high cost of employee training, more product choices and other similar support services, } \\
\text { retailers in traditional channels can still offset these costs through sales. } \\
\text { RA5 Despite the higher cost in support service and competition from other channels, retailers in traditional } \\
\text { channels can still earn profit from the products offered. }\end{array}$ & \\
\hline $\begin{array}{l}\text { Manufacture's } \\
\text { dependence }\end{array}$ & $\begin{array}{l}\text { MD1 very dependent on main retailers in traditional channel. } \\
\text { MD2 The main retailers in traditional channel are hard to be replaced. } \\
\text { MD3 The lost of main retailers in traditional channel will incur big price. } \\
\text { MD4 Most business comes from main retailers in traditional channel. }\end{array}$ & $\begin{array}{l}\text { Jap et al. (2000), } \\
\text { Payan et al. (2005) }\end{array}$ \\
\hline
\end{tabular}




\begin{tabular}{|c|c|c|}
\hline Research variable & Measurement standard & Reference source \\
\hline $\begin{array}{l}\text { Multi-channel } \\
\text { conflict }\end{array}$ & $\begin{array}{l}\text { MC1 The frequency of disagreement with traditional channels in pricing is very high. } \\
\text { MC2 The frequency of disagreement with traditional channels in issues related to customer segmentation is very } \\
\text { high. } \\
\text { MC3 The frequency of disagreement with traditional channels in product supply and promotional support is very } \\
\text { high. }\end{array}$ & $\begin{array}{l}\text { Coughlan et al. } \\
(2001)\end{array}$ \\
\hline Trust & $\begin{array}{l}\text { TR1 to ensure that traditional channels want to join in for channel cooperation to gain revenue. } \\
\text { TR2 to believe that both parties will consider each other's interests when making decisions. } \\
\text { TR3 Both parties believe that the information provided by the other party is authentic. } \\
\text { TR4 Traditional channels believe that their partners are professional enough and capable of completing channel } \\
\text { cooperation tasks. }\end{array}$ & Currall (2002) \\
\hline $\begin{array}{l}\text { Cooperation } \\
\text { performance }\end{array}$ & $\begin{array}{l}\text { CP1 Channel cooperation has significantly improved the profit margin. } \\
\text { CP2 Channel cooperation has significantly reduced the cost. } \\
\text { CP3 Channel cooperation has significantly improved the market share of products. } \\
\text { CP4 Channel cooperation has significantly enhanced the possibility of acheieveing cooperation goals between } \\
\text { channels. } \\
\text { CP5 Channel cooperation has significantly improved the satisfaction of cooperation between channels. } \\
\text { CP6 Channel cooperation has significantly improved the synergy between channels. }\end{array}$ & $\begin{array}{l}\text { Geyskens et al. } \\
\text { (1999), } \\
\text { Lyles et al. (1994) } \\
\text { Mohr et al. (1990) }\end{array}$ \\
\hline
\end{tabular}

\section{B. Data Collection}

Considering that the sample of the questionnaire should be in line with the background characteristics of the multichannel cooperative research and be representative in the geographical selection, this paper selected manufacturing companies with multi-channel supply chains in 14 provinces and municipalities in China (Beijing, Shanghai, Chongqing, Shandong, Jiangsu, Zhejiang, Fujian, Guangdong, Henan, Shanxi, Anhui, Hubei, Sichuan, and Yunnan) as a research sample, distributed 300 questionnaires through surveys, mailings, and e-mails and got back 258 questionnaires with a recovery rate of $86.0 \%$. In addition to the default of the answer items, the obvious extreme tendency of the answering results and the contradiction between the answer items were judged as invalid questionnaires, a total of 217 valid questionnaires were obtained, and the effective recovery rate was $72.3 \%$. Among the people filling out the questionnaire in state-owned and state-controlled enterprises (38.2\%), private enterprises $(32.7 \%)$, and foreign-funded and joint ventures $(29.1 \%)$, most employees are middle- and high-level personnel in the sales or channel management departments. People with college degree or above account for $82.2 \%$, and people working for more than 5 years account for $80.6 \%$. They have the awareness and sensitivity to the industry required by the survey.

\section{EMPIRICAL RESULTS AND ANALYSIS}

\section{A. Reliability and Validity Analysis}

The reliability is tested by Cronbach's $\alpha$ coefficient. The results of SPSS21.0 statistical software analysis show that the Cronbach's $\alpha$ coefficient of all variables is above 0.7 , which is consistent with the standard that $\alpha$ value should be above 0.6 in social science research, indicating that the questionnaire scale is good in measuring reliability. The Cronbach's $\alpha$ coefficient of the overall reliability of the questionnaire is 0.908, indicating that the whole questionnaire has good reliability and stability. The KMO value and the Bartlett sphericity test showed that the KMO value was 0.845 , indicating that the variables had the conditions for factor analysis. The validity test uses the factor analysis method. The test results show the load value of all factors is bigger than 0.6, in line with the standard that the load value should be above 0.4 . The interpretation degree of variable is above $50 \%$, indicating that each factor has a strong interpretation of the corresponding latent variable and has good structural validity. Further study can be carried out. The test results of reliability and validity are shown in "Table II". The mean value, standard deviation and correlation coefficient of each variable are shown in "Table III".

TABLE II. The ASSESSMENT OF CONSTRUCTS' RELIABILITY AND CONVERGENT VALIDITY

\begin{tabular}{|l|l|l|l|l|}
\hline \multicolumn{1}{|c|}{ Variable name } & Cronbach $\boldsymbol{\alpha}$ & \multicolumn{1}{c|}{ KMO } & \multicolumn{1}{c|}{ Factor load } & Cumulative interpretation \% \\
\hline Channel tracing capability & 0.906 & 0.878 & $0.694-0.874$ & 61.023 \\
\hline Reward coordination ability & 0.840 & 0.822 & $0.639-0.830$ & 61.254 \\
\hline Manufacture's dependence & 0.858 & 0.805 & $0.796-0.857$ & 70.162 \\
\hline Multi-channel conflict & 0.808 & 0.685 & $0.795-0.890$ & 72.544 \\
\hline Trust & 0.744 & 0.733 & $0.693-0.801$ & 54.840 \\
\hline Cooperation performance & 0.861 & 0.884 & $0.705-0.798$ & 59.474 \\
\hline
\end{tabular}

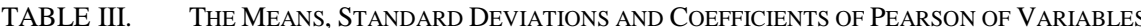

\begin{tabular}{|c|c|c|c|c|c|c|c|c|}
\hline Variable & Mean value & Standard deviations & 1 & 2 & 3 & 4 & 5 & 6 \\
\hline Manufacture's dependence & 3.732 & 0.870 & $0.149 * *$ & $0.190 * *$ & 1 & & & \\
\hline Trust & 3.787 & 0.642 & $0.274 * * *$ & $0.354 * * *$ & 0.009 & 0.102 & 1 & \\
\hline Cooperation performance & 3.611 & 0.626 & $0.401 * * *$ & $0.283 * * *$ & -0.034 & $0.258 * * *$ & $0.538 * * *$ & 1 \\
\hline
\end{tabular}

${ }^{\text {a. }}$ Note: * indicates a significance level $\mathrm{P}<0.05$, ** indicates a significance level $\mathrm{P}<0.01$, and $* * *$ indicates a significance level $\mathrm{P}<0.001$ (the same below). 


\section{B. Research Hypothesis Test}

The model was fitted by AMOS software, where $\chi 2 / \mathrm{df}=1.201, \quad \mathrm{RMR}=0.077, \quad \mathrm{RMSEA}=0.031, \quad \mathrm{CFI}=0.910$, IFI $=0.909$, PGFI $=0.762$, indicating that the structural equation model fits well. The standardized path coefficients are shown in "Fig. 2". The action coefficient of channel tracing capability, reward coordination capability, manufacturer's dependence, multi-channel conflict, trust and cooperation performance are $0.372 * * *,-0.008,-0.139 \dagger$ $0.235^{*}, 0.398^{* * *}$, respectively, so $\mathrm{H} 1, \mathrm{H} 3, \mathrm{H} 4, \mathrm{H} 5$ assumptions are verified while $\mathrm{H} 2$ assumption fail to be verified.

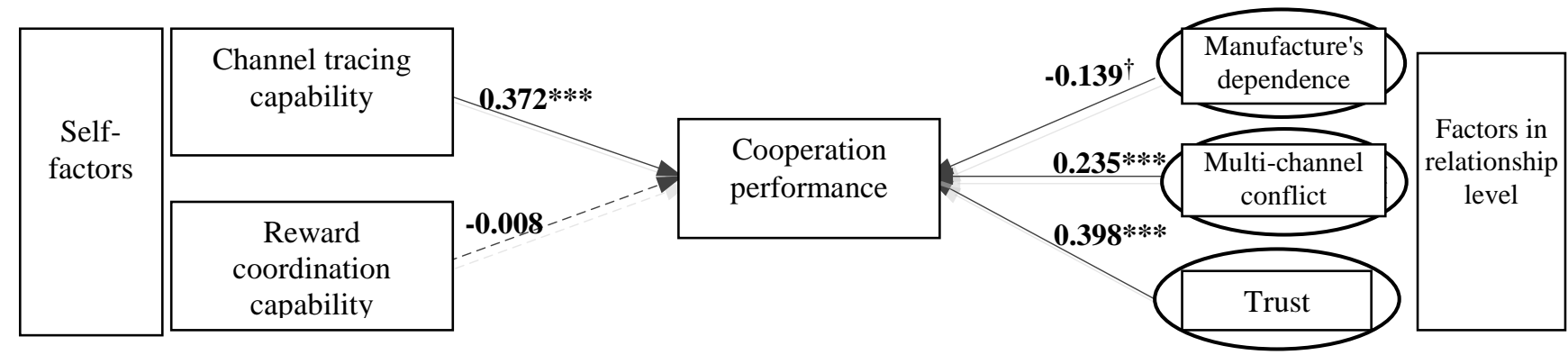

Fig. 2. Path coefficients in structural equation modeling.

\section{Analysis of Results}

As regards to channel tracing capability has positive influence on improving cooperation performance (influence coefficient is $0.372 * * *$ ), while the effect of reward coordination capability is not significant. It shows that in the multi-channel context, manufacturers still tend to use the channel tracing method to coordinate in cooperation, while the role of reward coordination capability is not sufficient, and cannot effectively stimulate traditional retailers for channel cooperation.

As regard to factors in relationship level, manufacturer dependence has a negative impact on improving the performance of channel cooperation $\left(-0.139^{\dagger}\right)$, indicating that manufacturers have become more and more dependent on traditional retailers in multi-channel services, and they can obtain smaller share in cooperative performance. Multichannel conflicts have a significant positive effect on cooperation performance $\left(0.235^{* * *}\right)$, and the average level of conflicts is 3.166. On the one hand, multi-channel conflicts have not yet had a negative impact on the cooperation between manufacturers and traditional retailers. Manufacturers can actively deal with conflicts in cooperation, turn conflicts into new opportunities for cooperation, and improve cooperation performance. On the other hand, the positive effects of channel cooperation exceed the negative effects of channel conflicts on cooperation performance. Trust has the greatest positive effect on cooperation performance $(0.398 * * *)$, indicating that trust among channel members is a key factor in channel performance and an important role in channel cooperation.

\section{MANAGEMENT IMPLICATIONS}

The individual factors of manufacturers have a positive impact on channel cooperation behavior, and manufacturers should further strengthen their own capabilities to promote multi-channel cooperation. The channel tracing capabilities of manufacture are used well in multi-channel collaboration, but reward coordination capabilities fail to produce the same level of positive impact, indicating that manufacturers need to further strengthen their reward coordination capabilities. Although reward coordination strategies may make the growth rate of short-term revenue of manufactures stagger under centralized decision, it will be a win-win situation from the perspective of long-term revenue of channel members, customer effectiveness, supply chain efficiency and competitiveness.

The cooperation factors of channel members have an important influence on channel cooperation. First of all, manufacturers must correctly use the positive role of trust to promote channel cooperation, so that the relationship between channel members is always in a virtuous circle of mutual trust, cooperation and mutual benefit. Secondly, manufacturers should pay attention to and correctly understand the impact of conflicts. Although the current multi-channel conflicts are at a low level, and the significantly increased positive market effects are greater than the negative effects caused by conflicts, manufacturers can be stimulated to adopt positive countermeasures and strengthen cooperation with traditional retailers. Manufacturers must timely discover and coordinate operational problems in multiple channels through conflicts, so that channel conflicts can be transformed into benign competition among channel members. Moreover, since the marginal profit brought by the electronic channel is larger than the traditional channel, and from the perspectives of information control, customer demand satisfaction, and market expansion, manufacturers will actively use the electronic direct sales channel, but from the perspective of channel structure, service function and regional influence traditional channels have an irreplaceable role in the sales process. Therefore, regardless of the degree of power dependence of manufacturers in the supply chain, manufacturers should cherish the cooperative resources of traditional channels, play the complementary effect with the traditional retail channels, and at the same time strengthen their own ability, seek mutual dependence, long-term and fair cooperation to promote the improvement and 
development of multi-channel supply chain with traditional retailers.

\section{CONCLUSION}

This paper explores the factors affecting the channel cooperation in multi-channel supply chain, but focuses on the relevant factors at the micro level of core enterprise manufacturers, and does not study external factors such as environmental uncertainty, industry competition, and the stage of cooperation. In the measurement of data, the relative indicators of cooperative performance may have certain limitations, and the objective data of different time nodes may be used for improvement in the future. In addition, in view of the fact that manufacturers and traditional retailers in the multi-channel supply chain have increased the difference in cooperative games due to horizontal competition, whether traditional retailers have the same perception for channel cooperation as manufacturers, further research is needed.

\section{REFERENCES}

[1] Wallace D W, Johnson J L, Umesh U. Multichannels strategy implementation: The role of channel alignment capabilities [J]. Decision Sciences, 2009, 40(4):869-900

[2] Webb K L. Managing channels of distribution in the age of electronic commerce [J]. Industrial Marketing Management, 2002, 31(2):95-102.

[3] Guo Chunrong, Chen Gongyu, Zhong Zuchang. Commentary of supply chain with hybrid distribution channel [J]. Foreign Economics \& Management (in Chinese), 2008, 30(9):22-27. (in Chinese)

[4] Rosenbloom B. Multi-channel strategy in business-to-business markets: Prospects and problems [J]. Industrial Marketing Management, 2007, 36(1):4-9.

[5] Zhang J, Farris P W, Irvin J W, Kushwaha T, Steenburgh T J, Weitz B A. Crafting integrated multichannel retailing strategies [J]. Journal of Interactive Marketing, 2010, 24(2):168-180.

[6] Wang Guocai, Zhao Yanhui. Channel segmentation and integration in multi-channel conflict Management: A research framework focused on E-business [J]. Economic Management Journal (in Chinese), 2009, 31(8):106-112. (in Chinese)

[7] Chiang W. Product availability in competitive and cooperative dualchannel distribution with stock-outbased substitution [J]. European Journal of Operational Research, 2010, 200(1):111-126.

[8] Ai Xingzheng, Tang Xiaowo, Ma Yongkai. Performance of forecasting information sharing between traditional channel and Echannel $[\mathrm{J}]$. Journal of Management Sciences in China, 2008, 11(1):12-21. (in Chinese)

[9] Yu Aimin, Liu Liwen. Competing and coordination strategies for the dual channel under stochastic demand and cooperative promotion[J]. Journal of Industrial Engineering /Engineering Management, 2012, 26(1):151-155. (in Chinese)

[10] Xu G, Dan B, Zhang X, Liu C. Coordinating a dual-channel supply chain with risk-averse under a two-way revenue sharing contract [J]. International Journal of Production Economics, 2014, 147(1):171-179. (in Chinese)

[11] Steinfield C. Does online and offline channel integration work in practice? [C]. Workshop on E-Commerce Impacts Revisited, DIWBerlin, 2004.

[12] Gallino S, Moreno A. Integration of online and offline channels in retail: The impact of sharing reliable inventory availability information [J]. Management Science, 2014, 60(6):1434-1451

[13] Frohlich M T. E-integration in the supply chain: Barriers and performance [J]. Decision Sciences, 2002, 33(4):537-556.
[14] Mahajan J, Radas S, Vakharia A J. Channel strategies and stocking policies in uncapacitated and capacitated supply chains [J]. Decision Sciences, 2002, 33(2):191-222.

[15] Stern L W, Ansary A I. Marketing channels [M]. London: PrenticeHall International, 1992.

[16] Dwyer F R, Oh S. Output sector munificence effects on the interna political economy of marketing channels [J]. Journal of Marketing Research, 1987, 24(4):347-358

[17] Balasubramanian S. Mail versus mall: A strategic analysis of competition between direct marketers and conventional retailers [J]. Marketing Science, 1998, 17(3): 181-195.

[18] Magrath A J, Hardy K G. A strategic paradigm for predicting manufacturer-reseller conflict [J]. European Journal of Marketing, 1989, 23(2):94-108.

[19] Andaleeb S S, Anwar S F. Factors influencing customer trust in salespersons in a developing country [J]. Journal of International Marketing, 1996, 4(4):35-52.

[20] Hagel J, Singer M. Unbundling the corporation [J]. Harvard Busines Review, 1999, 77(2):133-141.

[21] Geyskens I, Steenkamp J, Kumar N. A meta-analysis of satisfaction in marketing channel relationships [J]. Journal of Marketing Research 1999, 36(2):223-238

[22] Lyles M A, Baird I S. Performance of international joint ventures in two Eastern European countries: the case of Hungary and Poland [J]. Management International Review, 1994, 34(4):313-329.

[23] Mohr J, Nevin JR. Communication strategies in marketing channels a theoretical perspective [J]. The Journal of Marketing, 1990, 54(4):36-51.

[24] Jap S D, Ganesan S. Control mechanisms and the relationship life cycle: Implications for safeguarding specific investments and developing commitment [J]. Journal of Marketing Research, 2000, 37(2): 227-245

[25] Payan J M, McFarland R G. Decomposing influence strategies: Argument structure and dependence as determinants of the effectiveness of influence strategies in gaining channel member compliance [J]. Journal of Marketing: A Quarterly Publication of the American Marketing Association, 2005, 69(3):66-79.

[26] Coughlan A T, Anderson E, Stern L W, Ansary A I. Marketing channels [M]. London: Prentice-Hall, 2001.

[27] Currall S C, Inkpen A C. A multilevel approach to trust in joint ventures [J]. Journal of International Business Studies, 2002 33(3):479-495. 